University for Business and Technology in Kosovo

UBT Knowledge Center

Oct 27th, 4:45 PM - 7:15 PM

\title{
Integrating Resilience, Green Building and BIM in Architecture theory and practice
}

\author{
Ferhat Bejtullahu \\ University for Business and Technology, ferhat.bejtullahu@ubt-uni.net
}

Follow this and additional works at: https://knowledgecenter.ubt-uni.net/conference

Part of the Architecture Commons

\section{Recommended Citation}

Bejtullahu, Ferhat, "Integrating Resilience, Green Building and BIM in Architecture theory and practice" (2017). UBT International Conference. 7.

https://knowledgecenter.ubt-uni.net/conference/2017/all-events/7

This Event is brought to you for free and open access by the Publication and Journals at UBT Knowledge Center. It has been accepted for inclusion in UBT International Conference by an authorized administrator of UBT Knowledge Center. For more information, please contact knowledge.center@ubt-uni.net. 


\title{
Integrating Resilience, Green Building, and BIM in Architecture theory and practice
}

\author{
Ferhat Bejtullahu \\ UBT - Higher Education Institution, Prishtinë, Kosovë, \\ ferhat.bejtullahu@ubt-uni.net
}

\begin{abstract}
The paper contents qualitative research that covers the scope of Resilience, Green Building, and BIM (Building Information Modeling) concepts implementation. The objective of the paper is to facilitate the discussion on the question how these concepts can be integrated to apply in architecture theory and practice by making science-based building decisions that will improve the overall performance of construction projects. Research is done in global and regional context focused in the Republic of Kosovo.

The specific objective of this paper is to facilitate socially innovative actions and initiatives as a primary source for integration of resilience, green building and BIM technology in the daily life. Participating and observing group discussions with architects, spatial planners, and environmental professionals helped to uncover trends in theory and practice, and dive deeper into the problem. State of art literature review on this topic and personal interviews in daily work helped to analyze and compare the local, regional and international implementation of concepts. Results of the research paper will help to understand of the global and regional architects and planning professionals in order for there to be clear the need for promoting the notion of BIM, resilience and green building and integrating them in theory and practice.

In conclusions will be described conditions for integrating new concepts interconnected in new inclusive strategies. Integration will narrow the gap between the EU and Balkan countries. In recommendations will be proposed framework that can potentially enhance community decisions by creating an opportunity to achieve synergy among different interconnected multispectral stakeholders in the building sector.
\end{abstract}

Keywords: Integration, Resilience, Green Building, and BIM

\section{Introduction}

The construction industry boom in the region (Republic of Kosova) is characterized by contaminated buildings during which many buildings estates had serious shortcomings whereas most of these should not have building permission. The crisis also showed how the urban sprawl period actually contributed to the segregation between different communities and income groups especially in the use of public infrastructure, services, public spaces, and technology.

Most of the existing buildings and design regulations in the region need improving energy efficiency and then expanding into areas of resilience, water conservation, mobility optimization, and comfort. The need for improvement is premised on the importance of achieving benefits of productivity using BIM technology, being environmentally responsible by adapting Green Building concept and improving social Resilience by creating resilient buildings-cities. 
Use of technology (current BIM applications) may be helpful and useful for integrating Resilience and Green Building in architecture theory and practice. This can be done by promoting these concepts and retrieving data for checking compliance with national and international regulations, codes, and standards. Promotion and practice will increase collaboration between building code checkers (or inspectors) and other project participants (i.e. architects, engineers, and project managers) in regard to increasing resilience, energy efficiency and changes management throughout the course of the project. As part of measures to reach a global market and standards, regional countries have to integrate environmental impact assessment, urban resilience and BIM technology use into national building codes. Favorable government initiatives and mandates driving the demand for integrating this concept in theory and practice

\section{Background}

In Kosovo, as in regional developing countries building sector often has a key role and a close relationship with architecture, urban planning sectors in promoting projects for urban development. The importance of economic development is important for initiating coalitions among different parties. An example of this can be seen in the new some buildings development planning projects in Kosovo. The framework of these projects allows private stakeholders to develop projects according to the demand of the market. The municipal government carries only the responsibility to lease the lands and has few regulations for land use control. Several initiatives of planning especially relevant to this concepts were recorded in policy-making during this stage. The characteristic of considering the current situation is important. There is no BIM and Green Construction integration in National Building Codes, no disaster monitoring center, to support emergency decision-making. There are missing policy-making initiatives in setting goals and initiating actions for implementing these concepts.

The current regional economic difficulties have affected most practitioners within the building industry and, as a result, many building companies and contractors are bidding for fewer projects, resulting in low-quality buildings. Building companies and contractors are now operating under increasingly difficult conditions. In this context, it is hard for them the introduction of new software applications, system upgrades and adaptation of new concepts. The transition to Building Information Modelling BIM from traditional 2D CAD by Kosovo building companies and contractors is in introduce phase. With wider use of the term in policy, practice, and planning, resilience is increasingly seen in academic debates as a contested concept (MacKinnon, D. \& Derickson, K. D., 2013).

The process of BIM, Resilience and Green building concepts adaptation by professionals in the region is a relatively slow compared with the international colleagues. There are many reasons for this, including lack of resources, lack of awareness, ignorance, misunderstanding, and adversity. The lack of promotion and training opportunities within the industry has meant that very few people possess the basic requirement to successfully range at a level which would be considered efficient. BIM is the new way of operating and it is gaining momentum; the industry simply cannot turn a blind eye to the technology or it will be left behind. The industry must therefore adapt and change current working practices in order to compete with other established and recognized BIM nations. This paper will evaluate concepts in the international context and, investigate if these approaches can be transferred to the Kosovo building industry. This paper will also aim to identify obstacles and drivers for Kosovo firms, contractors and Government Departments with regard to concepts adoption, as well as the behavioral and cultural elements which are preventing adoption in Kosovo. In order to overcome obstacles, improve resilience and reduce $\mathrm{CO} 2$ emissions the research findings will represent new approach with a conceptual framework for the implementation of integrated concepts, for both public and private sector organizations. 


\section{Research question}

In developed countries, these concepts have become a universal topic in architecture, planning, environmental management policy discussions, and practice. Developments around these concepts in Balkan region are often associated with the need of resisting any change and rebounding to the primary state.

Problem statement: Communities in region are very slow in implementing new concepts for safety, commodity after rebounding to the primary state from negative impact of natural and human-made disasters

To solve this problem this research question raised: Why we need and how to integrate Resilience, Green building and BIM in theory and practice?

\section{Main and the specific objective}

The main objective of the paper is to facilitate the discussion on the question how this concept can be used to apply in architecture theory and practice by making science-based building decisions that will improve the performance of a whole building. Research is done in regional context focused in the Republic of Kosovo.

The specific objective of this paper is to facilitate socially innovative actions and initiatives as a primary source of resilience and green building through bottom-up creativity among communities and stakeholders to help the integration of BIM, resilient architecture, spatial planning and environmental assessments in theory and practice.

This paper seeks to bridge the theoretical gap that exists between role of resilience theories in architectural, spatial planning and environment context and missing building strategies that will enhance community resilience applied in building the industry by creating synergetic missed opportunity to achieve synergy among different stakeholders. (Building Officials, Code/Standard Developers, and Policymakers, anyone interested in quality in buildings at a high level).

Reason for doing this research is that successfully integrating Resilience, Green Building and BIM in theory and practice will help building resilient communities in the region, those that are capable of mitigating the impact of natural and human-made disasters. They can do this by actively influencing and preparing for economic, technological, social and environmental change. Integrating of effective measures for promoting social development and use of the new scientific and technological instruments is important to reduce the disparities between regional developing and industrialized countries

\section{Synergies and interrelations between concepts}

Concepts are individual and self-supported, but they have relative interrelations and synergy. BIM tools are strong constant contributors in energy simulation performance for Green Construction certification. The interrelations between BIM, Resilience and Green Construction comes in all project stages considering of construction life cycle. (Figure 1) 


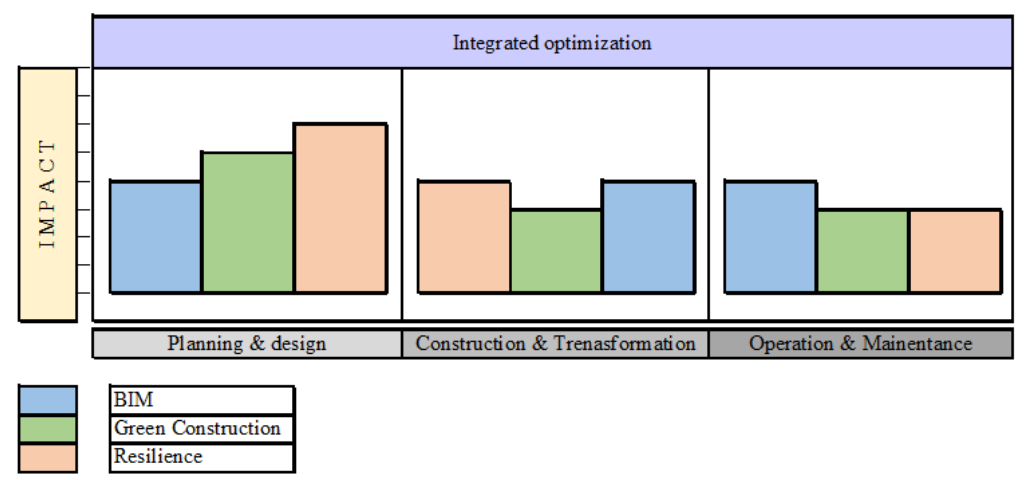

Figure 1 Interrelations between BIM, Resilience and Green Construction

\section{Literature review}

To discuss BIM technology, resilience and green building concepts there is a need to understand the evolving nature how it has been adopted in architecture, planning and environmental management fields of sciences.

BIM can aid in the aspects of sustainable design which include: building orientation, building massing (that is used to analyze building form and optimize the building envelope), daylighting analysis, water harvesting (that is used to reduce water needs in a building), energy modeling (that helps reducing energy needs and to analyze how renewable energy options can contribute to low energy costs), sustainable materials (that helps reducing material needs by using recycled materials) and site and logistics management (to reduce waste and carbon footprints). (Krygiel, E., and Nies, B, 2008)

The construction industry however still is just starting to see the benefits and challenges an organization phases by deciding to implement BIM (Ferhat Bejtullahu, Violeta Nushi, Enis Jakupi, 2015). One use of BIM is to provide the customer a glance of how the building will be experienced when finished. The implementation of BIM requires that the architect handle over a digital 3D model of the design done in a compatible program. All participants in the project use a common database to store drawings and exchange information with each other. (Bergmark, 2004; Norén, 2009).

In planning theory and practice, resilience thinking has been invoked to analyze the relationships between communities and the environment (Wilkinson, 2012)

The resilience of buildings and architecture does not only refer to incidents - such as formulating immediate responses to crisis situations or incidents such as earthquakes, floods or other disasters in vulnerable areas - but also considers long-term mitigation and adaptation strategies to face building buildings as a social, spatial and environmental challenge. These strategies have to result in making infrastructure and buildings resilient to manmade and natural disasters. The number of refugees, asylum-seekers and internally displaced people around the world has topped 65 million, the United Nations High Commissioner for Refugees said Monday, Jun 20, 2016. As of December 2015, there were 65.3 million displaced people, according to a report from the refugee agency.

Resilience in buildings terms are often seen as the property of a material (elasticity) to retain its original form (rebounding) after being subjected to temporary stress. Engineering resilience is therefore defined as the amount of disturbance or time to recover back into equilibrium following a disturbance (Gunderson, 2009). Ecological resilience from the perspective of environmental management is defined as: "the persistence of relationships within a system and [...] the ability 
of these systems to absorb changes of state variables, driving variables, and parameters, and still persist" (Holling, 1973). These aspects of resilience as two distinct characteristics define whether an ecosystem could return to a prior state or transform into a different but stable state. Whereas engineering resilience gives the optimal design features in which an entity could recover back into its original form after a certain level of disturbance, ecological resilience explains the situation of multiple equilibria in which a system could adapt to the change by bouncing forth into a slightly different form (Davoudi, S., Brooks, E.\& Mehmood, A, 2013).

Green building certification systems are useful guides during the design to record performance progress, to compare buildings and to document the outcomes and/or strategies used in the building Green building is a completely different concept than resilient building, but they are actually closely related and interconnected with BIM technology too. Green building is also known as a sustainable or "high performance' building. Green or sustainable, building is the practice of creating and using healthier and more resource-efficient models of building, renovation, operation, maintenance, and demolition. (EPA, 2017).

\section{Methods}

State of art literature review on this concept and personal interviews in daily work helped to analyze and compare the local, regional and international implementation of concepts. Participating and observing group discussions with architects, spatial planners, and environmental professionals and helped to uncover trends in thought and opinions, and dive deeper into the problem.

Analyzing global and regional trends of the last 15 years, it is easy to identify that technological evolution and knowledge economy has affected all sectors including building industry. Effects of this evolution are creating possibilities for usage of resources in innovative and synergistic ways of buildings in creating resilient architecture, spatial planning, and sustainable environment. Conditions of buildings, architecture and urban resilience in a regional context.

Architects are contributing to city resilience. Generally, city resilience needs to be assessed, planed and eventually (after chronic stresses and acute shocks they experience) recovered based on social, spatial and environmental components and their dimensions.

The conceptual framework for Integrating Resilience, Green Building, and BIM in theory and practice. 


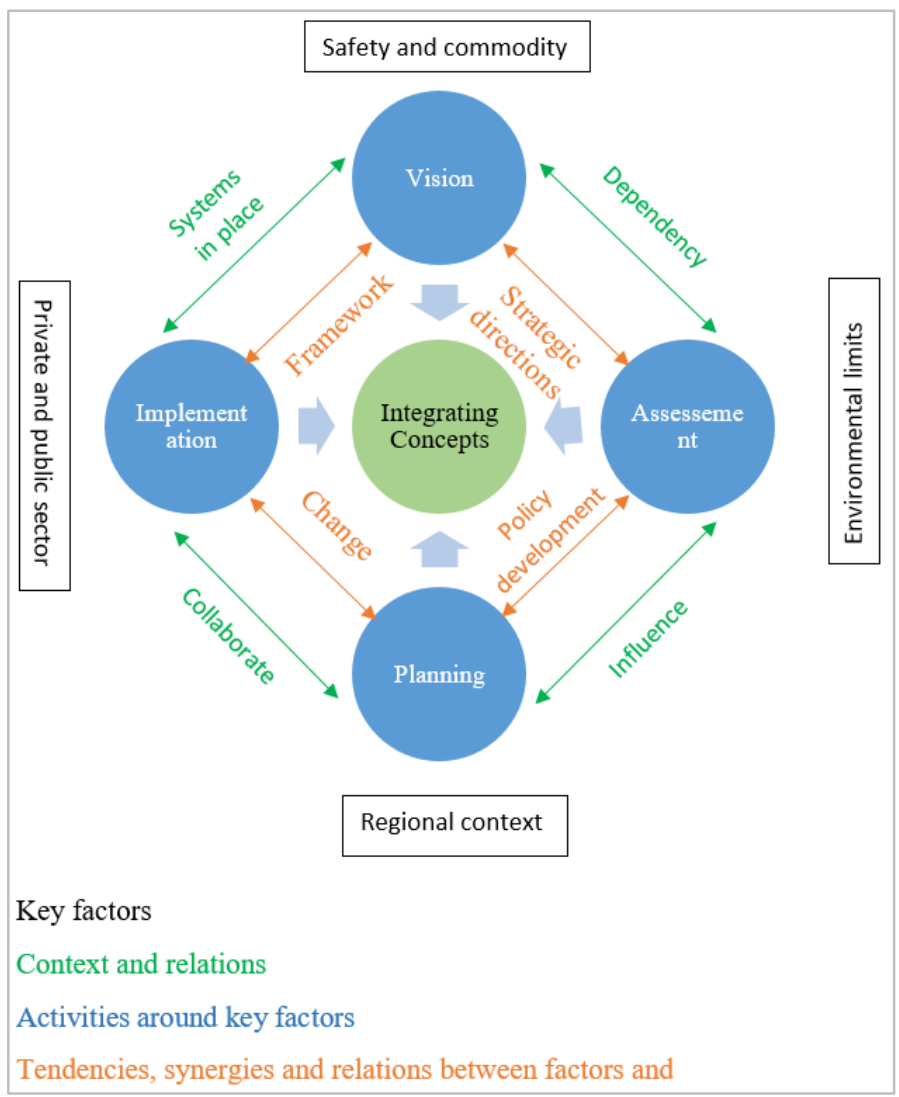

Figure 2 Integration of Resilience, green building and BIM concepts and different factors

The conceptual framework (Figure 2) represents the way to achieve integrating Concepts of Resilience, Green Building and BIM in the architecture, engineering, and construction (AEC) industry through identification of: Key factors; Context and Relations; Activities around key factors; and Tendencies, synergies and relations between factors.

The main idea of this integration is to identify the relationship among Resilience, Green Building, and BIM that can help to find positive interactions and synergies between concepts.

The regional countries share a comparable political history, characterized by a transitional economy to a post-socialist system, and relatively young state building after an experience of civil war. The countries of the Western Balkans share the challenges of transition from planned to market economies and, with the exception of Albania, face the trials of overcoming civil war and an exodus of their peoples. (Brian Evans (Main Report Writer, Glasgow Urban Laboratory, The Glasgow School of Art), 2016)

Trends of migration is an issue that influences buildings and resilience in Balkans. The crises in the Balkans in the 1990s caused the movement of about 4 million people to Germany, Switzerland, and Austria. Between 2001 and 2008, the level of net immigration in the EU was even higher than that in the US - traditionally a country of immigration. (Gebhardt). By 1995, the region witnessed the displacement of more than 2 million people, creating unique housing 
challenges. (Brian Evans (Main Report Writer, Glasgow Urban Laboratory, The Glasgow School of Art), 2016)

Cities in the region offer economically successful career but the larger metropolitan areas face constraints for development, including overpriced buildings, landownership unclarity and environmental degradation, pollution, expensive and inefficient infrastructure, social segregation, unorganized public transport, and traffic congestion.

Global trends are calling for a necessary change of theory and practice in building production. It is estimated that at least 95 percent of all buildings on Earth are produced without the involvement of a professionally trained architect. (Vestbro, 2014). Simplifying procedures by integrating concepts and using technology will change trends toward the increased role of architects in the creation of resilient architecture, society, and cities.

\section{Results}

Conceptual framework model has been designed to provide structure and the relationships that influence concepts integration. The model takes a systematic approach that looks at the key agents and linkages operating within. This analytical tool with several variations and contexts is used to describe conceptual distinctions and organized ideas into integrated process for identifying the role of buildings in resilience. The model's principal hypothesis is that, through improving the buildings quality and relationships within the environment, synergies and innovative responses, resilience can be fully developed. The integrated approach haze all of the assets and resources within architecture, spatial planning and environmental context to ensure synergies in future positive change. Integration is based on the building improved performance, is achieved by having the technology and the systems in place which help both individuals and institutions to collaborate effectively in developing solutions to challenges.

\section{Conclusion and recommendations}

The construction industry and environmental issues continue to harmfully affect cities in the region. The key aspects are inadequate buildings, climate change, water, air and soil quality, and extreme weather situations and natural disasters. Urban sprawl contributes not only to soil sealing and increasing traffic, they also increase air pollution, climate change, and local heat islands. The current state of the economy, buildings and of the urban lifestyle dominant in the region have to move towards creating resilient architecture, city and integrated environmental sustainability in the context of spatial planning.

For creating resilient architecture, spatial planning in different environmental context there is a need for buildings strategies and actions at multiple levels to facilitate strategies that optimize buildings. With a shared community vision, strategic planning that prioritizes buildings, and coordinated implementation can result in a resilient architecture, more livable places for current and future generations to grow and thrive - communities that are better prepared for future social and environmental challenges. This will help regional cities to survive, adapt and grow no matter what kinds of chronic stresses and acute shocks they experience.

Many of the strategies needed to achieve resilience are exactly the same strategies that are promoted for years in the green building concept (e.g. well-insulated homes) that will keep their occupant's safe if the power goes out or interruptions in heating fuel occur. The solutions are largely the same, but the motivation is one of life-safety, rather than simply doing the right thing. We need to practice green building because it will keep us safe-a powerful motivation-and this may be the way to finally achieve widespread adoption of such measures. The change of the 
culture and new way of thinking is a must and had to be considered carefully in case of integrating these concepts in theory and practice.

Integrating Resilience, Green Building and BIM technology with international and local Construction Codes (Kosova is in the process of creation), this is the turning point in the industry. Fast integration and implementation of these concepts using technology will have multiple benefits for regional states, especially in reducing the gap between developed countries and region. Countries in the region can integrate these concepts by improving social relations, supporting socio-political empowerment (property tax) and fulfilling the needs of the people for resilient, quality and environmentally friendly buildings as a priority. This includes integrated and responsible resource management during the planning, construction, and use of buildings.

\section{Recommendations}

By starting a new approach with integration of these concepts will facilitate solutions development towards their implementation with full potential in the life cycle of projects. Starting solution will be an integrated delivery project.

The public and private sectors, including codes and standards organizations, have to do significant progress and to integrate these concepts into the design of buildings and infrastructure.

Recommendations help create a path forward for practitioners at all levels of government and across sectors including the code and standard development process to enhance resilience, green building and BIM technology in construction management practice.

Based on theoretical analyzes, findings from compared conditions of residential buildings and urban resilience in a regional context, and global trends the framework for integrating resilient buildings into implemented strategies are recommended. Recommendations consist of using creative and synergistic ways for the writing the resilient plan and setting a vision, developing goals, doing resilience assessment, planning and implementation.

Vision: To identify and empower of people meeting, talking to each other and together shaping buildings and city's vitality-resilience. To reduce social and communication barriers need so that there is a friendlier interaction between the communities and nations. Recognize concepts as an opportunity to advance a shared vision of more resilient, and sustainable community-architecture and city in different environmental context.

Assessment: Use concepts to identify theoretical and practical gaps between the current status and the desired state, and use the data gathered to inform goals, priorities, and strategies. Sharing of technology and information should continue at rapid step so that the nations in the region can make advantage of modern techniques of operations that are available in the EU countries.

Planning: Integrate buildings considerations into planning across all sectors by integrating planning activities and ensuring that decision makers understand potential buildings impacts of decisions.

Implementation: Use strategies in creative and synergistic ways so that actions of all sectors maximize resilience in architecture, spatial planning, and environmental context. Establish a learning process so that buildings impact in community resilience are continuously evaluated and used to inform iterative decision making. 


\section{References}

1. Brian Evans (Main Report Writer, Glasgow Urban Laboratory, The Glasgow School of Art),. (2016). TOWARDS A CITY-FOCUSED, PEOPLE-CENTRED AND INTEGRATED APPROACH TO THE NEW URBAN AGENDA. UNECE region: UH-Habitat.

2. Davoudi, S., Brooks, E.\& Mehmood, A. (2013). Evolutionary resilience and strategies for climate adaptation, Planning Practice and Research, 28(3), pp. 307-322.

3. EPA. (2017, 06 30. 06. 2017). Green Building. Retrieved from Green Building Home: https://archive.epa.gov/greenbuilding/web/html/

4. Ferhat Bejtullahu, Violeta Nushi, Enis Jakupi. (2015). Architects role in change influenced by technology and increasing urban data (BIM, GIS, and CODES) from global and local perspective. International Conference on Business, Technology, and Innovation (pp. 4653). Durres, Albania: CIP Biblioteka Kombëtare e Kosovës "Pjetër Bogdani” ISBN 978 9951-550- $13-0$.

5. Gebhardt. (n.d.). 2014.

6. Holling, C. (1973). Resilience and stability of ecological systems, Annual Review of Ecology and Systematics, 4, pp. 1-23.

7. Krygiel, E., and Nies, B. (2008, 07 01). Successful sustainable design with building information modeling, Retrieved from Green BIM:: Wiley.com

8. MacKinnon, D. \& Derickson, K. D. (2013). From resilience to resourcefulness. A critique of resilience policy and activism, 37(2), pp. 253-270.

9. Vestbro, D. U. (2014). Paradigm Shifts in architecture. Architecture and planning under different political systems (p. 10). Stockholm: ARC•PEACE.

10. Wilkinson, C. (2012). Insights and issues for planning theory, Planning Theory, 11(2), Social-ecological resilience: pp. 148-169. 